\title{
Examining minimal important change of the Canadian Occupational Performance Measure for subacute rehabilitation hospital inpatients
}

\author{
Kanta Ohno ${ }^{1,2^{*}} \mathbb{0}$, Kounosuke Tomori $^{1}$, Tatsunori Sawada ${ }^{1}$ and Ryuji Kobayashi ${ }^{2}$
}

\begin{abstract}
Background: The Canadian Occupational Performance Measure (COPM) is an individualized patient-reported outcome designed to evaluate the self-perceptions of a patient's occupational performance. Our study aimed to examine the minimal important change (MIC) in inpatients undergoing subacute rehabilitation. The MIC values were calculated using the three different anchor-based analyses with the transition index as an external criterion; the mean change method ( $M I C_{\text {MeanChange}}$ ), the receiver operating characteristic ( $\left.M I C_{R O C}\right)$ analysis, and the predictive modeling method adjusted for the proportion of improved patients $\left(\mathrm{MIC}_{\text {adjust }}\right.$ ). In this study, the $\mathrm{MIC}_{\text {adjust }}$ value was considered as the most valid statistical method. We recruited 100 inpatients with various health conditions from subacute rehabilitation hospitals. Data were collected twice: an initial assessment and a reassessment one month later. The systematic interview format (Five Ws and How) was used for both the initial and second assessments to prevent information bias (response shift).
\end{abstract}

Results: Three patients who indicated deterioration on the transition index were excluded from all analyses, and 97 patients were analyzed in this study. The MIC $_{\text {adjust }}$ values were 2.20 points (95\% confidence interval 1.80-2.59) for the COPM performance score and 2.06 points (95\% confidence interval 1.73-2.39) for the COPM satisfaction score. The $\mathrm{MIC}_{\text {Meanchange }}$ and $\mathrm{MIC}_{\mathrm{ROC}}$ values were considered less reasonable to interpret because the proportions of the improved patients subgroup were more than $50 \%$ (82.5\%).

Conclusions: The $\mathrm{MIC}_{\text {adjust }}$ value estimates from this study can help detect whether the patients' perceived occupational performance improved or did not change. The results support the multidisciplinary use of COPM in clinical practice and research on subacute rehabilitation inpatients.

Keywords: Canadian Occupational Performance Measure, Minimal clinically important difference, Patient-reported Outcome, Subacute rehabilitation hospital, Response shift

\footnotetext{
*Correspondence: ohnoknt@stf.teu.ac.jp

${ }^{1}$ Major of Occupational Therapy, Department of Rehabilitation, School of Health Science, Tokyo University of Technology, 5-23-22, Nishikamata, Ota-City, Tokyo 144-8535, Japan

Full list of author information is available at the end of the article
}

\begin{abstract}
Background
Occupational therapy is a health profession that operates on the principles of client-centeredness [1]. The World Federation of Occupational Therapy states: "The outcomes are client-driven and diverse and measured in terms of participation, satisfaction derived from occupational participation and/or improvement in occupational performance" [2]. Occupational performance is a person's
\end{abstract}


ability to perform the required activities, tasks, and roles of daily living and is categorized into three occupational dimensions: self-care, productivity, and leisure [3]. Occupational therapists are bound to evaluate various aspects of their clients' occupational performance, including the client's own perceptions [4].

The Canadian Occupational Performance Measure $(\mathrm{COPM})$ is a well-known patient-reported outcome measure (PROM) in rehabilitation [3], and is a patientspecific measure to identify and evaluate a patient's occupation as something that the patient "wants to do, needs to do, or is expected to do" (i.e., occupational performance) $[5,6]$. Through a semi-structured interview, patients prioritize up to five occupational problems that are the most urgent or important but difficult to perform $[5,6]$. The patient then rates each of the identified problems by self-evaluating their current PERFORMANCE score (COPM-P) and SATISFACTION with the current performance score (COPM-S) $[5,6]$. The COPM is flexible to use in various clinical settings without any target population-related limitations. It is used in over 40 countries and has been translated into more than 35 languages $[5,6]$. The COPM has become a global gold standard for clinical research and rehabilitation practice.

Some researchers have reviewed the psychometric properties of the COPM in various situations, and reported good validity, reliability (test-retest), and responsiveness [7, 8]. In a prior systematic review [9], however, no measurement properties met the criteria of the COnsensus-based Standards for the selection of health Measurement INstruments (COSMIN) methodology $[10,11]$ because some studies indicated sufficient quality of evidence, while others were of poor quality. In particular, regarding responsiveness, the quality of evidence was inconsistent because only two of the ten included studies met the COSMIN criteria $[12,13]$. In the COSMIN guidelines, responsiveness has been defined as "the ability of PROM to detect change over time in the construct to be measured" [14, 15]. Furthermore, interpretability is considered an important aspect in selecting PROMs, although it is not a measurement property [11]. Interpretability is defined as "the degree to which one can assign qualitative meaning (that is, clinical or commonly understood connotations) to a PROM's quantitative scores or change in scores" [16]. The original manual of the COPM indicated that a change of 2.0 points or more is regarded as a clinically important change [5], however, the methodology for calculating points is unclear, and the target sample is not described in detail.

There are multiple methodological approaches to calculate the minimal important change (MIC) [17, 18]. Kjeken et al. examined the MIC using a distribution method in adult patients with ankylosing spondylitis [19].
Eyssen et al. [13] investigated the MIC in home-dwelling adults using the anchor-based method that compares the change score of PROM with some other measures of change, considered an anchor or external criterion [17]. There is often a range in the MIC estimates that varies across the target population and clinical study context, because the MIC depends on the characteristics of the target population and the context [20]. Although, the MIC should be calculated for each target population, no studies have investigated the MIC of COPM in subacute patients using scientific methods. Therefore, the main objective of our study was to document the variability of the MIC values of the COPM using a common anchorbased calculation for inpatients undergoing various diagnoses in subacute rehabilitation hospitals.

\section{Methods}

\section{Study design and ethics}

This multicenter prospective longitudinal study was conducted in subacute rehabilitation hospitals in Japan. The study was performed in accordance with the ethical approval of the Tokyo Metropolitan University Ethics Committee (20052). All participants provided written informed consent before participating in the study.

\section{Participants}

Participants were selected from the occupational therapy departments of three subacute rehabilitation wards in Tokyo. The inclusion criteria for the patients were as follows: (a) admitted to subacute rehabilitation wards between July 2020 and March 2021 (9 months), (b) received client-centered occupational therapy from occupational therapists, (c) aged $\geq 20$ years, (d) able to understand written or spoken Japanese, (e) deemed to not have a severe cognitive impairment from their scores on the mini-mental state examination ([MMSE], i.e., a score of 20 or higher), and (f) had not been diagnosed or suspected to have an intellectual disability or cognitive impairment, and were not medically/psychiatrically unstable (based on a review of participants' medical history and medical chart).

The inclusion criteria of the occupational therapists were as follows: (a) had a minimum of at least six months of full-time clinical experience as an occupational therapist, (b) had attended educational sessions regarding scoring and interpretation of the COPM administered by the first author, (c) had read the COPM manual, and (d) had completed a total of 15 COPM pre-post administrations with patients.

\section{Canadian Occupational Performance Measure (COPM)}

The COPM is an individual measure that captures a client's self-perception of actual performance and 
satisfaction in everyday living $[5,21]$. The clients were asked to rate COPM-P and COPM-S for each of the prioritized occupations using an ordinal 10-point scale where $1=$ "not able to do it at all" and $10=$ "able to do it extremely well" or where $1=$ "not satisfied at all" and $10=$ "extremely satisfied" [5]. We obtained the average performance score by summing the ratings for the performance score over the prioritized problems and dividing them by the number of occupations. The average satisfaction scores were calculated in a similar manner [5].

\section{Transition index}

To derive the MIC values, we used a transition index [22, 23] as an anchor to capture the patient's impression of change for each of the occupational performances identified by the COPM. The question was: "To what degree have you perceived a change in problems of each identified occupation since the initial assessment?" The transition index was graded on a 7-point ordinal scale, where " $1=$ totally diminished" and " $7=$ much worse." The transition index describes the magnitude and direction of the change in perceived health status over a given period. Multiple studies have used the transition index as an external criterion for calculating the MIC [13, 17, $24]$. With reference to a previous study by Eyssen et al., those answering " $1=$ totally diminished," " $2=$ diminished," or " $3=$ slightly diminished" for at least three of the five problems on the transition index were labeled "Improved" (e.g., responders), patients answering " $4=$ no change" were labeled "No change" (e.g., nonresponders). Similarly, patients who indicated deterioration (" $5=$ slightly worse," " $6=$ worse," or " $7=$ much worse") for at least three of the five problems on the transition index were labeled "Deteriorated." Because this study focused on determining cutoff points of improvement in self-perception of occupational performance prioritized on the COPM, patients who were labeled "Deteriorated" were excluded from all analyses [13]. The anchors' validity was evaluated with Polyserial correlation coefficients between the transition index and the respective change scores of the COPM-P and COPM-S. The correlation between the change scores on the PROM and the anchor question should be at least 0.30 to assume validity of the anchor [25].

\section{Data collection}

The patients were assessed twice by occupational therapists who were bound to evaluate various aspects of their clients' occupational performance, including the client's own perceptions of the same occupational therapist in the initial assessment ( $\mathrm{T} 1$, within 1 week from admission to the hospital), and the reassessment (T2). The patient and the occupational therapist planned the reassessment together about one month after the initial assessment or if the therapy was coming to an end before one month. In the first assessment, we collected the demographic characteristics of the participants, including information on health conditions (i.e., age, diagnosis, and sex) and MMSE. Further, years of experience of the occupational therapists were obtained from a staff database. COPM-P and COPM-S were assessed in both the initial assessment and reassessment. After the reassessment of the COPM was complete, patients were asked about the transition index.

\section{Measurement method of COPM to prevent response shift}

To correctly interpret the longitudinal change score in PROMs, it must be assumed that the respondents' perceptions remain stable over time; however, several studies have indicated that the meaning of patients' selfevaluations may not be the same over time, a phenomenon called response shift [26-28]. Response shift is defined as "the change in the meaning of a person's selfevaluation of a target construct (e.g., QOL) over time" [29]. There are three types of response shifts: a change in the meaning of one's evaluation of a construct as a result of a change in one's internal standards of measurement (recalibration), a change in one's values (reprioritization), or a change in one's definition of the construct (reconceptualization) [29]. If a response shift occurs in the measurement of the COPM, the MIC cannot be detected correctly.

The structural equation model (SEM) is an accurate statistical analysis for detecting the response shift effects of PROMs [28]. However, the COPM is a PROM classified as "Individualized", and allows the participants to select their own personal concerns, unlike the measurements that use predetermined personal concerns in the responder's list of questionnaire items [30]. Hence, we thought that it was difficult to apply SEM to investigate the response shift of the COPM, because the items of the COPM are determined by the respondents. In this study, we modified the COPM interview to decrease the impact of the response shift effect, especially "recalibration." We used a systematic format that identifies problems more specifically, the "Five Ws and How" questions with reference to the method of identifying patient-centered goal setting by Randall et al. [31]. These questions were: "Who does the occupation? (subject)," "When do you do the occupation? (duration/frequency)," "Where do you do the occupation? (place)," "Why do you do the occupation? (reason/purpose)," and "How do you do the occupation? (method/procedure/means)." This format was used to facilitate patients' recall of their own internal standards of self-perceptions of identified occupations. 
At the reassessment, the therapists showed the patients their occupations identified at the first assessment using the "Five Ws and How," before the patients scored the COPM.

\section{Statistical analysis}

The normality of the distribution of continuous variables was tested using the Shapiro-Wilk test. We used the Mann-Whitney $U$ test for the comparison of change scores between the initial assessment (T1) and the reassessment (T2), and for the between-group comparisons.

In this study, we used three different anchor-based methods to examine MIC: the mean change method $\left(\mathrm{MIC}_{\text {MeanChange }}\right)$ [32], the receiver operating characteristic (ROC)-based method ( $\mathrm{MIC}_{\mathrm{ROC}}$ ) [16], and the anchor-based MIC based on predictive modeling method $\left(\mathrm{MIC}_{\text {predict }}\right)$ [33].

In the mean change method, $\mathrm{MIC}_{\text {MeanChange }}$ is defined as the change score on the measure of interest in the subgroup of patients that reported to be "a little better" (minimal important improvement) on the anchor question [32]. In the ROC method, sensitivity, specificity, and Youden index were calculated for COPM-P and COPM-S, whereby the Youden index $=$ sensitivity + specificity -1 [34]. In the current study, the highest Youden index was considered to represent the optimal $\mathrm{MIC}_{\mathrm{ROC}}$ value, which reflects the COPM change score that provides the optimal distinction between "Improved" and "No change." The area under the curve (AUC) for the ROC represents the probability that a client will be correctly identified by the COPM as "Improved." The AUC values can range from 0.5 , which indicates that prediction equals that of pure chance, to 1.0, which implies perfect accuracy in distinguishing "Improved" from "No change" [35]. In our study, AUC values $\geq 0.90$ was considered excellent accuracy, between 0.80 and 0.89 was considered good, between 0.70 and 0.79 was considered fair, and less than 0.70 was considered poor accuracy [36]. At this cutoff point (i.e., $\mathrm{MIC}_{\mathrm{ROC}}$ ), the diagnostic accuracy parameters of the COPM, sensitivity, specificity, positive predictive value (PPV), negative predictive value (NPV), accuracy, positive likelihood ratio (PLR), and negative likelihood ratio (NLR) were calculated, and their range was estimated at a $95 \%$ confidence interval.

The predictive modeling approach is related to the predicted probability that a patient belongs to the "Improved" group based on the anchor [33]. The $\mathrm{MIC}_{\text {predict }}$ was determined by logistic regression analysis, with the observed change score of the COPM as independent variable and the TI anchor as dependent variable [33]. The $\mathrm{MIC}_{\text {predict }}$ is defined as the change score associated with a likelihood ratio of 1 [33]. Recently, this approach has been considered more precise as compared to the ROC method ( $\left.\mathrm{MIC}_{\mathrm{ROC}}\right)$ [33].

When the proportion of the "Improved" patients differs from $50 \%$, the MIC will be biased. If more than $50 \%$ of the patients show "Improved" occupational performance, the MIC will tend to overestimate. If the percentage of "Improved" was not equal to $50 \%$, we applied a formula for the adjustment of proportions "Improved" to obtain $\mathrm{MIC}_{\text {adjust }}$ as a more accurate estimate of the MIC [33]. Therefore, in this study, we considered the $\mathrm{MIC}_{\text {adjust }}$ the most statistically accurate.

All statistical analyses were performed using EZR (Saitama Medical Center, Jichi Medical University, Saitama, Japan), which is a graphical user interface for R (The R Foundation for Statistical Computing, Vienna, Austria). More precisely, it is a modified version of $R$ commander designed to add statistical functions frequently used in biostatistics [37].

\section{Results}

\section{Participant population and identified occupations}

A total of 100 patients were enrolled in this study during the nine-month recruitment period. On the transition index, 80 of the 100 clients were labeled "Improved" (80\%), 17 were labeled "No change" (17\%), and $3(3 \%)$ were labeled "Deteriorated." Clients labeled "Deteriorated" $(\mathrm{n}=3)$ were excluded from all analyses, and finally, 97 patients were analyzed in the current study.

Demographic characteristics of the participants are presented in Table 1. Thirty-six patients were male (37.1\%), and the mean age was $73.6 \pm 12.6$ years. The diagnostic categories were stroke (38.1\%), orthopedic diseases (including hip fractures and spinal cord injury) (57.7\%), and disuse syndrome (a condition that is caused due to lack of physical activity, secondary to pneumonia and coronary occlusion) (4.1\%). Among the 97 patients, 400 occupational performance problems were identified through COPM interviews. The distributions of the three dimensions are shown in Table 1 . The most frequently prioritized problems were related to self-care activities $(n=207,51.8 \%)$. This was followed by the domains of productivity $(\mathrm{n}=141,35.3 \%)$ and leisure $(\mathrm{n}=52,13.0 \%)$. The most dominant occupational category was household arrangement $(n=133,33.3 \%)$.

\section{Scores of the COPM in comparison with anchor}

The distribution and mean change scores of the COPM per TI category are provided in Table 2. Of the 400 occupations, TI3 (A little improved) was the most frequent $(\mathrm{n}=145,36.3 \%)$. The total percentage of TI1 to TI3 represented the "Improved" group was $76.8 \%(\mathrm{n}=307)$, which was higher than that of the "No change (TI4)" 
Table 1 Participants' characteristics and identified occupations in the Canadian Occupational Performance Measure

\begin{tabular}{|c|c|c|c|c|c|c|}
\hline Variable & Category & Mean or count & & SD & MAX & MIN \\
\hline \multicolumn{7}{|l|}{ Patients ( $n=97)$} \\
\hline Males & & $36(37.1 \%)$ & & & & \\
\hline Age & & 73.6 & \pm & 12.6 & 97 & 36 \\
\hline \multirow[t]{3}{*}{ Diagnosis } & Stroke & $37(38.1 \%)$ & & & & \\
\hline & Orthopedic disease & $56(57.7 \%)$ & & & & \\
\hline & Disuse syndrome & $4(4.1 \%)$ & & & & \\
\hline MMSE & & 27.2 & \pm & 2.6 & 30 & 20 \\
\hline \multirow[t]{3}{*}{ FIM } & Total & 81.9 & \pm & 16.6 & 123 & 42 \\
\hline & Motor & 54.1 & \pm & 14.0 & 90 & 23 \\
\hline & Cognitive & 28.1 & \pm & 5.3 & 35 & 9 \\
\hline Domain & Aspect & Count & & & & \\
\hline \multicolumn{7}{|c|}{ Occupations identified by the COPM $(n=400)$} \\
\hline \multirow[t]{3}{*}{ Self-care $(n=207,51.8 \%)$} & Personal care & $128(32.0 \%)$ & & & & \\
\hline & Functional mobility & $63(15.8 \%)$ & & & & \\
\hline & Community management & $16(4.0 \%)$ & & & & \\
\hline \multirow[t]{3}{*}{ Productivity ( $n=141,35.3 \%)$} & Paid/unpaid work & $8(2.0 \%)$ & & & & \\
\hline & Household arrangement & $133(33.3 \%)$ & & & & \\
\hline & Play/school & $0(0 \%)$ & & & & \\
\hline \multirow[t]{3}{*}{ Leisure $(n=52,13.0 \%)$} & Quiet recreation & $16(4.0 \%)$ & & & & \\
\hline & Active recreation & $27(6.8 \%)$ & & & & \\
\hline & Socialization & $9(2.3 \%)$ & & & & \\
\hline \multicolumn{7}{|l|}{ Occupational therapist $(n=30)$} \\
\hline Experience years & & 5.9 & \pm & 3.4 & 16 & 2 \\
\hline
\end{tabular}

MMSE mini-mental state examination, FIM functional independence measure

Table 2 The distribution and mean change scores of the Canadian Occupational Performance Measure sorted by patients' responses in the transition index

\begin{tabular}{|c|c|c|c|c|c|c|c|c|c|}
\hline \multicolumn{4}{|c|}{ Occupations identified by the COPM $(n=400)$} & \multicolumn{3}{|c|}{ COPM-P change score } & \multicolumn{3}{|c|}{ COPM-S change score } \\
\hline \multicolumn{2}{|c|}{ Transition index } & \multicolumn{2}{|c|}{ Number of occupation (\%) } & \multicolumn{2}{|l|}{ Mean } & \multirow{2}{*}{$\frac{S D}{2.84}$} & \multicolumn{2}{|l|}{ Mean } & \multirow{2}{*}{$\begin{array}{l}\text { SD } \\
2.89\end{array}$} \\
\hline 1 & Much improved & $45(11.3)$ & $307(76.8)$ & 4.27 & \pm & & 4.62 & \pm & \\
\hline 2 & Improved & $117(29.3)$ & & 3.94 & \pm & 2.82 & 3.86 & \pm & 3.00 \\
\hline 3 & A little improved & $145(36.3)$ & & 2.62 & \pm & 2.33 & 2.78 & \pm & 2.57 \\
\hline 4 & No change & $88(22.0)$ & $88(22.0)$ & 1.09 & \pm & 2.72 & 0.89 & \pm & 2.56 \\
\hline 5 & A little worse & $4(1.0)$ & $5(1.3)$ & -2.25 & \pm & 1.50 & -0.50 & \pm & 4.73 \\
\hline 6 & Worse & $1(0.3)$ & & -5.00 & \pm & - & 0.00 & \pm & - \\
\hline 7 & Much worse & $0(0.0)$ & & - & \pm & - & - & \pm & - \\
\hline
\end{tabular}

COPM-P Canadian Occupational Performance Measure Performance score, COPM-S Canadian Occupational Performance Measure Satisfaction score

group ( $\mathrm{n}=88,22.0 \%)$ and the "Deteriorated (TI5 to TI7)" group $(\mathrm{n}=5,1.3 \%)$.

Table 3 shows the COPM score distribution for the "Improved" and "No change" groups. Comparing the initial assessment (T1) versus the reassessment (T2), COPM-P and COPM-S increased significantly only in the "Improved" group $(\mathrm{p}<0.001)$. The change scores $(\mathrm{T} 2-\mathrm{T} 1)$ for the COPM-P and COPM-S were significantly higher in the "Improved" group compared to the "No change" group ( $\mathrm{p}=0.005, \mathrm{p}<0.001$, respectively).

The frequencies of the change scores of COPM-P and COPM-S are presented in Fig. 1. Regarding the COPM-P, 3-point improvement (+3 points) was the most frequent $(\mathrm{n}=16,20.0 \%$, MAX: +7.6 points, MIN: 
Table 3 Results of the Canadian Occupational Performance Measure $(n=97)$

\begin{tabular}{|c|c|c|c|c|c|c|c|c|c|c|c|c|c|c|c|}
\hline \multirow[t]{2}{*}{ Variable } & \multirow[t]{2}{*}{ Group } & \multicolumn{4}{|c|}{ T1: Initial assessment } & \multicolumn{4}{|c|}{ T2: Reassessment } & \multicolumn{4}{|c|}{ T2-T1: Change score } & \multirow{2}{*}{$\begin{array}{l}\text { T1 vs T2 } \\
P \text {-value }\end{array}$} & \multirow{2}{*}{$\begin{array}{l}\text { T2-T1: } \\
\text { Change } \\
\text { score } \\
\text { Improved vs } \\
\text { No change } \\
P \text {-value }\end{array}$} \\
\hline & & Mean & & SD & $95 \% \mathrm{Cl}$ & Mean & & SD & $95 \% \mathrm{Cl}$ & Mean & & SD & $95 \% \mathrm{Cl}$ & & \\
\hline \multirow[t]{2}{*}{ COPM-P } & Improved $(\mathrm{n}=80)$ & 4.1 & \pm & 2.3 & $(3.6-4.6)$ & 7.1 & \pm & 1.9 & $(6.7-7.5)$ & 3.2 & \pm & 2.1 & $(2.7-3.7)$ & $<0.001^{*}$ & $0.005^{*}$ \\
\hline & No change $(n=17)$ & 3.0 & \pm & 2.1 & $(1.9-4.0)$ & 4.4 & \pm & 2.5 & $(3.1-5.7)$ & 1.4 & \pm & 2.1 & $(0.3-2.5)$ & 0.068 & \\
\hline \multirow[t]{2}{*}{ COPM-S } & Improved $(\mathrm{n}=80)$ & 3.8 & \pm & 2.2 & $(3.3-4.3)$ & 7.0 & \pm & 1.9 & $(6.6-7.4)$ & 3.0 & \pm & 2.1 & $(2.5-3.5)$ & $<0.001^{*}$ & $<0.001^{*}$ \\
\hline & No change $(n=17)$ & 2.8 & \pm & 1.9 & $(1.8-3.8)$ & 3.7 & \pm & 2.2 & $(2.6-4.9)$ & 0.9 & \pm & 1.3 & $(0.2-1.5)$ & 0.219 & \\
\hline
\end{tabular}

COPM-P Canadian Occupational Performance Measure Performance score, COPM-S Canadian Occupational Performance Measure Satisfaction score, 95\% CI 95\% confidence interval

${ }^{*} \mathrm{p}<0.01$
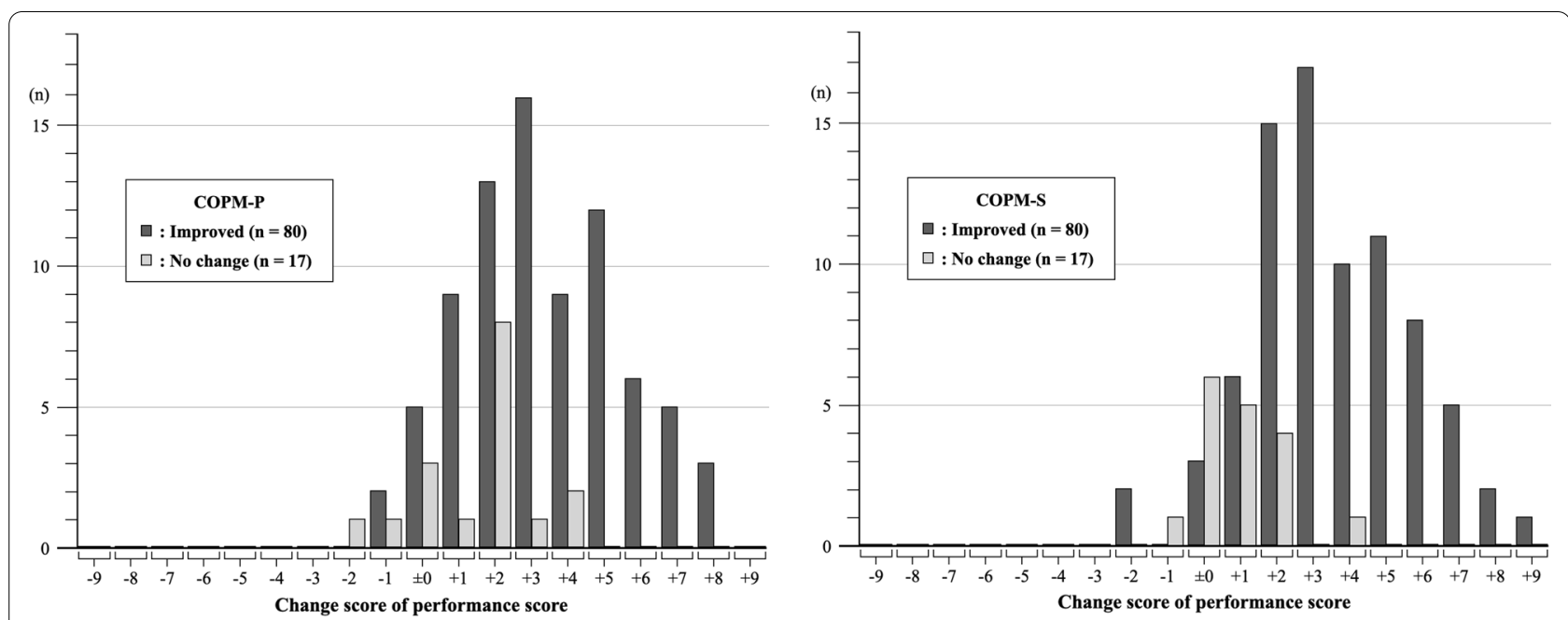

Fig. 1 Histogram of the change scores of the Canadian Occupational Performance Measure Performance score and Satisfaction score

-1.8 points) in the "Improved" group, whereas 2-point improvement $(+2$ points $)$ was the most frequent $(\mathrm{n}=8,47.1 \%$, MAX: +3.4 points, MIN: -2.2 points) in the "No change" group. As for the COPM-S, 3-point improvement ( +3 points) was the most frequent $(\mathrm{n}=17,21.3 \%$, MAX: +8.6 points, MIN $:-2.0$ points $)$ in the "Improved" group, whereas no change $( \pm 0$ point) was the most frequent $(n=6,35.3 \%$, MAX: +3.6 points, MIN: -1.8 points) in the "No change" group.

The correlations between anchor instrument and COPM change scores were 0.42 for the COPM-P and 0.66 for the COPM-S.

MIC calculation: the mean change method (MIC Meanchange) $_{\text {) }}$ As shown in Table 4, the $\mathrm{MIC}_{\text {MeanChange }}$ values that represented the mean change score in participants who reported "A little better" on the transition index were 2.62 points and 2.78 points for COPM-P and COPM-S, respectively.

\section{MIC calculation: the ROC method (MICROC)}

Table 4 presents the MIC of the COPM-P and COPM$\mathrm{S}$ to detect whether the occupational performance "Improved" or "No change" was observed, and to compare the diagnostic accuracy parameters. The Youden indexes were highest when the COPM-P score (i.e., $\mathrm{MIC}_{\mathrm{ROC}}$ ) was 1.75 points based on sensitivity of 0.70 , specificity of 0.71 , and COPM-S was calculated to be 2.25 points based on sensitivity of 0.66 , specificity of 0.94 (Table 4). The $\mathrm{MIC}_{\mathrm{ROC}}$ of the COPM-P was below the cutoff point (2.0 points) in the COPM manual [5]. In contrast, the $\mathrm{MIC}_{\mathrm{ROC}}$ of COPM-S was above the suggested cutoff point in the COPM manual [5]. 
Table 4 The MIC values and diagnostic accuracy parameters of the COPM-P and COPM-S

\begin{tabular}{|c|c|c|c|c|c|c|}
\hline \multirow[t]{3}{*}{ Parameters } & \multicolumn{3}{|l|}{ COPM-P } & \multicolumn{3}{|l|}{ COPM-S } \\
\hline & \multirow[t]{2}{*}{ Estimate } & \multicolumn{2}{|c|}{$95 \%$ confidence interval } & \multirow[t]{2}{*}{ Estimate } & \multicolumn{2}{|c|}{$95 \%$ confidence interval } \\
\hline & & Lower & Upper & & Lower & Upper \\
\hline$M I C_{\text {MeanChange }}$ & 2.62 & 2.24 & 3.00 & 2.78 & 2.36 & 3.20 \\
\hline $\mathrm{MIC}_{\mathrm{ROC}}$ & 1.75 & - & - & 2.25 & - & - \\
\hline Area under the Curve & 0.72 & 0.58 & 0.85 & 0.84 & 0.75 & 0.93 \\
\hline Sensitivity & 0.70 & 0.59 & 0.80 & 0.66 & 0.55 & 0.76 \\
\hline Specificity & 0.71 & 0.44 & 0.90 & 0.94 & 0.71 & 1.00 \\
\hline Positive Predictive Value & 0.92 & 0.82 & 0.97 & 0.98 & 0.90 & 1.00 \\
\hline Negative Predictive Value & 0.33 & 0.19 & 0.51 & 0.37 & 0.23 & 0.53 \\
\hline Accuracy & 0.70 & 0.60 & 0.79 & 0.71 & 0.61 & 0.80 \\
\hline Positive Likelihood Ratio & 2.38 & 1.12 & 5.04 & 11.26 & 1.67 & 75.90 \\
\hline Negative Likelihood Ratio & 0.43 & 0.27 & 0.67 & 0.36 & 0.26 & 0.50 \\
\hline$M I C_{\text {predict }}$ & 2.71 & 2.27 & 3.16 & 2.79 & 2.35 & 3.22 \\
\hline $\mathrm{MIC}_{\text {adjust }}{ }^{*}$ & 2.20 & 1.80 & 2.59 & 2.06 & 1.73 & 2.39 \\
\hline
\end{tabular}

COPM-P Canadian Occupational Performance Measure Performance score, COPM-S Canadian Occupational Performance Measure Satisfaction score

${ }^{*} \mathrm{MIC}_{\text {adjust }}$ : adjusted $\mathrm{MIC}_{\text {predict }}$ for the proportion of improved patients

\section{MIC calculation: the predictive modeling method ( MIC $_{\text {predict }} /$ MIC $_{\text {adjust }}$ )}

We found that the $\mathrm{MIC}_{\text {predict }}$ values were 2.71 (95\% CI $2.27,3.16)$ points and $2.79(95 \%$ CI $2.35,3.22)$ points for COPM-P and COPM-S, respectively. The $\mathrm{MIC}_{\text {predict }}$ values were adjusted because the proportion of "Improved" patients was $82.5 \%$, which was not equal to $50 \%$. After adjusting for the proportion "Improved", the $\mathrm{MIC}_{\text {adjust }}$ values were slightly decreased to 2.20 (95\% CI 1.80, 2.59) points and 2.06 (95\% CI 1.73, 2.39) points for COPM-P and COPM-S, respectively.

\section{Discussion}

\section{Comparison with previous studies}

This is the first study to propose estimates for the interpretation of MIC in COPM scores using three anchorbased methodologies. The MIC values varied depending on the MIC analysis methods. Eyssen et al. indicated that the optimal cutoff points $\left(\mathrm{MIC}_{\mathrm{ROC}}\right)$ of the COPM-P and COPM-S were 0.90 points (AUC: 0.85 ) and 1.45 points (AUC: 0.85), respectively, using the ROC curve analysis with transition index as an external standard [13]. Moreover, Tuntland et al. determined the $\mathrm{MIC}_{\text {MeanChange }}$ of COPM using a 5-point rating scale as an external standard [38], and Kjeken et al. calculated the measurement error (smallest detectable difference) of the COPM using the distribution method [19].

In our study, the $\mathrm{MIC}_{\text {MeanChange }}$ values were higher than $\mathrm{MIC}_{\mathrm{ROC}}$ and $\mathrm{MIC}_{\text {predict }}$ values for both COPM-P and COPM-S (Table 4). However, the $\mathrm{MIC}_{\text {MeanChange }}$ estimates do not reflect a true threshold for minimal improvement because it is defined as the mean change score of the subgroup who reported being "a little better" [33]. The $\mathrm{MIC}_{\mathrm{ROC}}$ values of the COPM-P and COPM-S were 1.75 and 2.25 points, respectively. As a result of ROC analysis, the cutoff value of COPM-P did not indicate sufficient predictive accuracy, with an AUC of 0.72 (95\% CI $0.58-$ $0.85)$ [17, 39], based on PPV of 0.92 and PLR of 2.38. On the other hand, the predictive accuracy of the COPM-S was good, with an AUC of 0.84 (95\% CI 0.75-0.93) [17, 39], based on PPV of 0.98 and PLR of 11.26. In the COSMIN checklist, ROC analysis is recommended to assess the responsiveness for continuous scores, such as the COPM $[10,11]$.

However, the MIC will be biased and overestimated if more than $50 \%$ of the participants are perceived as "Improved" [33]. The $\mathrm{MIC}_{\text {predict }}$ can be adjusted when the proportions of improved patients differ from 50\% $\left(\mathrm{MIC}_{\text {adjust }}\right)$ [33]. Hence, the methodology of our research is based on statistical and academic criteria, and the $\mathrm{MIC}_{\text {adjust }}$ values were considered more suitable than $\mathrm{MIC}_{\text {MeanChange }}$ and $\mathrm{MIC}_{\mathrm{ROC}}$ values.

Furthermore, target populations in all of the above studies were in the chronic phase or under stable conditions, including outpatients with various conditions [13], home-dwelling older adults [38], and home-dwelling patients with ankylosing spondylitis [19]. In contrast, inpatients with varying diagnoses in subacute rehabilitation hospitals were recruited for this study. Within two months after the onset of disabling diseases, patients in Japan are eligible for admission to a subacute rehabilitation hospital to receive early and intensive rehabilitation 
[40]. Therefore, it is suggested that the patients in this study can recover naturally due to their admission to the subacute hospital shortly after the onset of disabling diseases. To the best of our knowledge, this is the first study to calculate the MIC values of the COPM in subacute settings.

\section{Measurement accuracy of the COPM}

The COPM is classified as "Individualized" in the types of PROM, which allows the participants to select their own personal concerns, unlike the measurements that use predetermined personal concerns in the responder's list of questionnaire items [30]. In fact, Eyssen et al. reported that the concordance rate of prioritized problems using COPM between the first and second assessment with a time interval of seven days (SD 1.6, range 4-14) was only $66 \%$ [41]. Verkerk et al. also reported a concordance rate of $74 \%$, similar to that reported by Eyssen et al. [42]. Because a patient's perception may change over time, "recalibration," a type of the response shift effect defined as "changes in the internal standards" [42] in the COPM, was likely to occur. Furthermore, regarding the scoring system of the COPM, some studies indicated that patients were not familiar with scoring on scales and had difficulty converting the self-evaluation of their occupational performance into a number [43-45]. In particular, difficulties in quantifying self-perception increase with age $[46,47]$.

The SEM is an accurate statistical analysis for detecting the response shift effects of PROMs [28]. However, it is difficult to adopt SEM to investigate the COPM because its items are determined depending on the respondents (i.e., classified as "Individualized") [30]. The then test is the formerly used method to detect the response shift effect, especially recalibration [48]. In the then test, patients are asked to retrospectively rate (then measure) the initial assessment at the time of reassessment. Since the reassessment and then measure are administered at the same time, these two types of ratings are considered to have been evaluated based on the same internal criteria [49]. However, patients were required to accurately remember how they were functioning in the past, because in the then test there is a possibility of the patient's responses being affected by recall bias [48, 50]. In the current study, we applied a systematic interview format (i.e., "Five Ws and How") to identify patients' occupations in more detail. During the reassessment, patients were asked to rate their self-perception of occupational problems while referring to the identified occupations in the initial assessment, in order to minimize response shift effects and recall bias [51-53]. We believe that this format may help therapists and patients share occupational problems in greater detail and improve measurement accuracy. When researchers and clinicians apply the MIC results in this study, it is necessary to specify occupations using the same measurement methodology.

\section{Study limitation}

There are four major limitations in this study that could be addressed in future research. First, in general, the MIC values probably vary among the characteristics of the target population (i.e., diagnoses, ages, and stage of disease); therefore, further studies need to be performed according to specific patient groups. The second limitation is small sample size. The smallish sample size may cause increasing standard deviations, therefore patient heterogeneity might negatively affect the measure's ability to discriminate between "No change" and "A little improved." The third limitation concerns the measurement error of the TI (anchor). In this study, the proportion of the patients who were shown as "Improved" on the transition index was not equal to $50 \%$. It might be possible that patients did not accurately recognize a difference between "No change" and "A little improved" at TI. Finally, in this study, we used a systematic interview format, the "Five Ws and How" to reduce the response shift effects of the COPM. However, this interview technique was our original, and there is no research to examine the response shift when applying the "Five Ws and How." Thus, further research is needed to show evidence reducing recall bias using this method.

\section{Conclusion}

Our study aimed to examine MIC values to distinguish between inpatients in the subacute stage who have a minimal important change in COPM-P and COPM-S and those who have none, using three different methodologies. The $\mathrm{MIC}_{\text {adjust }}$ values were established to be 2.20 and 2.06 points for COPM-P and COPM-S, respectively. We used a systematic interview guide, the "Five Ws and How," to identify more detailed and minimized response shift effects. These findings support the interpretation of the meaning of intervention outcomes and facilitate the goal-setting process.

\section{Abbreviations}

PROMs: Patient-reported outcome measures; COSMIN: COnsensus-based Standards for the selection of health Measurement INstruments; COPM: Canadian Occupational Performance Measure; COPM-P: Canadian Occupational Performance Measure Performance score; COPM-S: Canadian Occupational Performance Measure Satisfaction score; MIC: Minimal important change; MMSE: Mini-mental state examination; ROC: Receiver operating characteristic; AUC: Area under the curve; PPV: Positive predictive value; NPV: Negative predictive value; PLR: Positive likelihood ratio; NLR: Negative likelihood ratio; FIM: Functional independence measure; SD: Standard deviation; Cl: Confidence interval; TP: True positive; FN: False negative; FP: False positive; TN: True negative. 


\section{Acknowledgements}

The authors thank all the clients and occupational therapists who participated in this study.

\section{Authors' contributions}

KO: Data interpretation, data analysis, and manuscript preparation. KT: Data interpretation, data analysis, and manuscript revision. TS: Manuscript revision. RK: Manuscript revision. All authors read and approved the final manuscript.

\section{Funding}

This study was supported by JSPS KAKENHI (Grant Number 19K19925).

\section{Availability of data and materials}

All data generated or analyzed during this study are included in this published article.

\section{Declarations}

\section{Ethics approval and consent to participate}

This study was performed in accordance with the ethical approval of the Tokyo Metropolitan University Ethics Committee (20052). All participants provided informed consent to participate in this study, which was approved by our institutional review board.

\section{Consent for publication}

Not applicable.

\section{Competing interests}

The authors declare that they have no competing interests.

\section{Author details}

${ }^{1}$ Major of Occupational Therapy, Department of Rehabilitation, School of Health Science, Tokyo University of Technology, 5-23-22, Nishikamata, Ota-City, Tokyo 144-8535, Japan. ${ }^{2}$ Department of Occupational Therapy, Graduate School of Human Health Sciences, Tokyo Metropolitan University, Tokyo, Japan.

Received: 16 July 2021 Accepted: 13 December 2021 Published online: 20 December 2021

\section{References}

1. Whalley Hammell KR (2015) Client-centred occupational therapy: the importance of critical perspectives. Scand J Occup Ther 22(4):237-243

2. World Federation Occupational Therapists (2010) Position statement on client-centredness in occupational therapy. https://apeto.com/assets/ servicios-de-to-en-pr\%C3\%A1cticas-basadas-en-los-colegios-ni\%C3\% B1os-y-adolescentes--ingl\%C3\%A9s.pdf. Accessed 15 July 2020

3. Townsend EA, Polatajko HJ (2007) Advancing an occupational therapy vision for health, well-being, and justice through occupation, 2nd edn. CAOT Publications ACE, Ottawa

4. Carpenter L, Baker GA, Tyldesley B (2001) The use of the Canadian Occupational Performance Measure as an outcome of a pain management program. Can J Occup Ther 68(1):16-22

5. Law MC, Baptiste S, Carswell A, McColl MA, Polatajko H, Pollock N (2019) Canadian occupational performance measure: COPM. CAOT Publications ACE, Ottawa

6. Law M, Baptiste S, McColl M, Opzoomer A, Polatajko H, Pollock N (1990) The Canadian occupational performance measure: an outcome measure for occupational therapy. Can J Occup Ther 57(2):82-87

7. Carswell A, McColl MA, Baptiste S, Law M, Polatajko H, Pollock N (2004) The Canadian Occupational Performance Measure: a research and clinical literature review. Can J Occup Ther 71(4):210-222

8. Yang SY, Lin CY, Lee YC, Chang JH (2017) The Canadian occupational performance measure for patients with stroke: a systematic review. J Phys Ther Sci 29(3):548-555

9. Ohno K, Tomori K, Sawada T, Seike Y, Yaguchi A, Kobayashi R (2021) Measurement properties of the canadian occupational performance measure: a systematic review. Am J Occup Ther 75(6). https://doi.org/10.5014/ajot. 2021.041699

10. Terwee CB, Prinsen CAC, Chiarotto A, Westerman MJ, Patrick DL, Alonso J et al (2018) COSMIN methodology for evaluating the content validity of patient-reported outcome measures: a Delphi study. Qual Life Res 27(5):1159-1170

11. Mokkink LB, de Vet HCW, Prinsen CAC, Patrick DL, Alonso J, Bouter LM et al (2018) COSMIN Risk of Bias checklist for systematic reviews of patient-reported outcome measures. Qual Life Res 27(5):1171-1179

12. Chenq YH, Rodger S, Polatjko H (2002) Experiences with the COPM and client-centred practice in adult neurorehabilitation in Taiwan. Occup Ther Int 9(3):167-184

13. Eyssen ICJM, Steultjens MPM, Oud TAM, Bolt EM, Maasdam A, Dekker $J$ (2011) Responsiveness of the Canadian Occupational Performance Measure. J Rehabil Res Dev 48(5):517

14. Prinsen CA, Vohra S, Rose MR, Boers M, Tugwell P, Clarke M et al (2016) How to select outcome measurement instruments for outcomes included in a "Core Outcome Set" — a practical guideline. Trials 17(1):449

15. Prinsen CAC, Mokkink LB, Bouter LM, Alonso J, Patrick DL, de Vet HCW et al (2018) COSMIN guideline for systematic reviews of patient-reported outcome measures. Qual Life Res 27(5):1147-1157

16. Mokkink LB, Terwee CB, Patrick DL, Alonso J, Stratford PW, Knol DL et al (2010) The COSMIN checklist for assessing the methodological quality of studies on measurement properties of health status measurement instruments: an international Delphi study. Qual Life Res 19(4):539-549

17. Copay AG, Subach BR, Glassman SD, Polly DW Jr, Schuler TC (2007) Understanding the minimum clinically important difference: a review of concepts and methods. Spine J 7(5):541-546

18. Wright AA, Cook CE, Baxter GD, Dockerty JD, Abbott JH (2011) A comparison of 3 methodological approaches to defining major clinically important improvement of 4 performance measures in patients with hip osteoarthritis. J Orthop Sports Phys Ther 41(5):319-327

19. Kjeken I, Dagfinrud H, Uhlig T, Mowinckel P, Kvien TK, Finset A (2005) Reliability of the Canadian Occupational Performance Measure in patients with ankylosing spondylitis. J Rheumatol 32(8):1503-1509

20. Revicki D, Hays RD, Cella D, Sloan J (2008) Recommended methods for determining responsiveness and minimally important differences for patient-reported outcomes. J Clin Epidemiol 61(2):102-109

21. Law M (2016) Measurement in occupational therapy: scientific criteria for evaluation. Can J Occup Ther 54(3):133-138

22. Husted JA, Cook RJ, Farewell VT, Gladman DD (2000) Methods for assessing responsiveness: a critical review and recommendations. J Clin Epidemiol 53(5):459-468

23. Hagg O, Fritzell P, Oden A, Nordwall A (2002) Simplifying outcome measurement: evaluation of instruments for measuring outcome after fusion surgery for chronic low back pain. Spine (Phila Pa 1976) 27(11):1213-1222

24. Reddy VK, Parker SL, Patrawala SA, Lockney DT, Su PF, Mericle RA (2013) Microvascular decompression for classic trigeminal neuralgia: determination of minimum clinically important difference in pain improvement for patient reported outcomes. Neurosurgery 72(5):749-754 (discussion 54)

25. Devji T, Carrasco-Labra A, Qasim A, Phillips M, Johnston BC, Devasenapathy $\mathrm{N}$ et al (2020) Evaluating the credibility of anchor based estimates of minimal important differences for patient reported outcomes: instrument development and reliability study. BMJ 369:m1714

26. Barker RN, Sealey CJ, Polley ML, Mervin MC, Comans T (2017) Impact of a person-centred community rehabilitation service on outcomes for individuals with a neurological condition. Disabil Rehabil 39(11):1136-1142

27. van Leeuwen CM, Post MW, van der Woude LH, de Groot S, Smit C, van Kuppevelt D et al (2012) Changes in life satisfaction in persons with spinal cord injury during and after inpatient rehabilitation: adaptation or measurement bias? Qual Life Res 21(9):1499-1508

28. Sajobi TT, Brahmbatt R, Lix LM, Zumbo BD, Sawatzky R (2018) Scoping review of response shift methods: current reporting practices and recommendations. Qual Life Res 27(5):1133-1146

29. Sprangers MA, Schwartz CE (1999) Integrating response shift into health-related quality of life research: a theoretical model. Soc Sci Med 48(11):1507-1515

30. Deshpande PR, Rajan S, Sudeepthi BL, Abdul Nazir CP (2011) Patientreported outcomes: a new era in clinical research. Perspect Clin Res 2(4):137-144 
31. Randall KE, McEwen IR (2000) Writing patient-centered functional goals. Phys Ther 80(12):1197-1203

32. de Vet HCW, Terwee CB, Mokkink LB, Knol DL (2011) Measurement in medicine: a practical guide. Cambridge University Press, Cambridge

33. Terluin B, Eekhout I, Terwee CB, de Vet HC (2015) Minimal important change (MIC) based on a predictive modeling approach was more precise than MIC based on ROC analysis. J Clin Epidemiol 68(12):1388-1396

34. Youden WJ (1950) Index for rating diagnostic tests. Cancer 3(1):32-35

35. Parker SL, Adogwa O, Paul AR, Anderson WN, Aaronson O, Cheng JS et al (2011) Utility of minimum clinically important difference in assessing pain, disability, and health state after transforaminal lumbar interbody fusion for degenerative lumbar spondylolisthesis. J Neurosurg Spine 14(5):598-604

36. Metz CE (1978) Basic principles of ROC analysis. Semin Nucl Med 8(4):283-298

37. Kanda Y (2013) Investigation of the freely available easy-to-use software "EZR" for medical statistics. Bone Marrow Transplant 48(3):452-458

38. Tuntland H, Aaslund MK, Langeland E, Espehaug B, Kjeken I (2016) Psychometric properties of the Canadian Occupational Performance Measure in home-dwelling older adults. J Multidiscip Healthc 9:411-423

39. Greiner M, Pfeiffer D, Smith RD (2000) Principles and practical application of the receiver-operating characteristic analysis for diagnostic tests. Prev Vet Med 45(1-2):23-41

40. Miyai I, Sonoda S, Nagai S, Takayama Y, Inoue Y, Kakehi A et al (2011) Results of new policies for inpatient rehabilitation coverage in Japan. Neurorehabil Neural Repair 25(6):540-547

41. Eyssen IC, Beelen A, Dedding C, Cardol M, Dekker J (2005) The reproduc ibility of the Canadian Occupational Performance Measure. Clin Rehabil 19(8):888-894

42. Verkerk GJ, Wolf MJ, Louwers AM, Meester-Delver A, Nollet F (2006) The reproducibility and validity of the Canadian Occupational Performance Measure in parents of children with disabilities. Clin Rehabil 20(11):980-988

43. Bodiam C (1999) The use of the Canadian Occupational Performance Measure for the assessment of outcome on a neurorehabilitation unit. Br J Occup Ther 62(3):123-126

44. Toomey M, Nicholson D, Carswell A (1995) The clinical utility of the Canadian Occupational Performance Measure. Can J Occup Ther 62(5):242-249

45. Kjeken I, Slatkowsky-Christensen B, Kvien TK, Uhlig T (2004) Norwegian version of the Canadian Occupational Performance Measure in patients with hand osteoarthritis: validity, responsiveness, and feasibility. Arthritis Rheum 51(5):709-715

46. Wressle E, Marcusson J, Henriksson C (2002) Clinical utility of the Canadian Occupational Performance Measure-Swedish Version. Can J Occup Ther 69(1):40-48

47. Soderman P, Malchau H (2000) Validity and reliability of Swedish WOMAC osteoarthritis index: a self-administered disease-specific questionnaire (WOMAC) versus generic instruments (SF-36 and NHP). Acta Orthop Scand 71(1):39-46

48. Howard GS, Dailey PR (1979) Response-shift bias: A source of contamination of self-report measures. J Appl Psychol 64(2):144-150

49. Ahmed S, Mayo NE, Wood-Dauphinee S, Hanley JA, Cohen SR (2004) Response shift influenced estimates of change in health-related quality of life poststroke. J Clin Epidemiol 57(6):561-570

50. Schwartz CE, Sprangers MAG (1999) Methodological approaches for assessing response shift in longitudinal health-related quality-of-life research. Soc Sci Med 48(11):1531-1548

51. Coughlin SS (1990) Recall bias in epidemiologic studies. J Clin Epidemiol 43(1):87-91

52. Althubaiti A (2016) Information bias in health research: definition, pitfalls, and adjustment methods. J Multidiscip Healthc 9:211-217

53. Schmier JK, Halpern MT (2004) Patient recall and recall bias of health state and health status. Expert Rev Pharmacoecon Outcomes Res 4(2):159-163

\section{Publisher's Note}

Springer Nature remains neutral with regard to jurisdictional claims in published maps and institutional affiliations.

\section{Submit your manuscript to a SpringerOpen ${ }^{\odot}$ journal and benefit from:}

- Convenient online submission

- Rigorous peer review

- Open access: articles freely available online

- High visibility within the field

- Retaining the copyright to your article

Submit your next manuscript at $\boldsymbol{\nabla}$ springeropen.com 